\title{
Nevertheless, I have persisted
}

\author{
Melissa J. Freeman \\ Medical Doctor, USA
}

In the early morning hours of one night, when I am a neurology resident on call at the hospital, I am paged to a stroke alert. This means I had to run to the emergency room to see, assess, and treat a critically ill patient. If the diagnosis is actually stroke, I have to decide whether to give a medication called TPA (a "clot-buster"), treat a brain hemorrhage, or call neurosurgery for emergency brain surgery.

In the trauma bay, there are no ER doctors or nurses. It is shockingly quiet. I go to my patient who is unconscious and unresponsive, with labored breathing and thread pulse. EMS has dropped her off and left. I do my neuro exam and realize she is near death and cannot be revived. She had been found at home alone in the bathtub. Someone had called for a wellness check probably because she had missed usual activities and had not been seen. The ambulance arrived, gave oxygen, and started a line to give intravenous fluid. I examine her, trying to be as gentle as I can. She smelled of death and yet she was breathing (barely) and her heart was still beating. There was no way she could have been revived. She had literally been on her deathbed when her death was interrupted by medics trained to rescue at all cost. I had to fulfill my legal obligation to intervene but did not want to do any of these things to her. I did not want to subject her to physical trauma because

Correspondence: Melissa J. Freeman, Vancouver, WA 98663, USA. E-mail: freeman.melissa@gmail.com

Key words: FSPHP; PHP; physician suicide; physician health program.

Received for publication: 24 October 2019

Accepted for publication: 21 November 2019.

This work is licensed under a Creative Commons Attribution NonCommercial 4.0 License (CC BY-NC 4.0).

${ }^{\circ}$ Copyright: the Author(s), 2019

Licensee PAGEPress, Italy

Qualitative Research in Medicine \& Healthcare 2019; 3:99-106 doi:10.4081/qrmh.2019.8638 of what I was 'supposed' to do. Soon her organs only remained functioning due to horribly invasive measures.

Because she has no living will, I am legally obligated to call for full resuscitation: a breathing tube through her mouth and vocal cords, into her lungs, a central line which delivers fluid through her veins into her heart. I call my sleeping, sleep deprived, overworked supervising attending who has no further advice. No family or friends showed up in the emergency room and she officially died not long after.

I've carried this weight with me ever since.

I collected so many stories of devastated lives during my pre-medical school shadowing, 4 years of medical school, 4 years of neurology residency, year of stroke fellowship, and $31 / 2$ years in practice. One of my patients was paralyzed from the waist down after a severe spinal cord infection after injecting drugs into her veins. She talked to me about how she was depressed because there was literally nothing that could be done about her paralysis. The shame and horror was palpable when we talked. I tried to help by listening to her, thinking of how to provide some rationale to keep going: her children, her spouse, anything. She felt that she was a burden to her family. Medications for depression had not helped her. She looked at me and said "my life will never improve, there is nothing I can do, I am a burden, and there is literally nothing to live for".

There was a teenager with terminal, rare cancer for which there was no available treatment. There was a commercial pilot who suffered a seizure and could no longer pursue his life passion. There were others.

There was not anything I could do to help other than to just listen.

I keep these stories with me. I sit with them, regularly, wondering how I could have done better. It is horrific to receive devastating news and it is horrific to deliver one.

The guilt of not being able to do more was something I had personal difficulty with and I became depressed.

In the state where I did my medical training, most primary care doctors do not treat things like depression or anxiety. After my fellowship training, I moved across the country to a state where my spouse and I knew hardly anyone. I developed severe work-related anxiety due to the unrealistic expectation of perfection by my clinic sur- 
rounding patient satisfaction scores not being perfect enough.

I could see clearly that it was going to be an issue if I let it go any further - which is why I sought help. A friend recommended her psychiatrist. I scheduled an appointment and they listened. I started an antidepressant and anxiolytic (low dose clonazepam). That was to help me sleep - I had developed severe sleep deprivation in my prior training, and the horrible anxiety I was experiencing would keep me up at night, ruminating over what I did or did not do that could have made me 'more perfect' in my job. Clonazepam, by the way, is an anxiolytic that has very minimal risk of abuse because it is not euphoria-inducing and is very safe pharmacologically. Anxiety and depression happen to medical professionals far more frequently than many would think. Depending on the screening tool used, it is as high as approximately $43 \%$ in resident physicians, and it increases with time. ${ }^{1}$ In fact, mental illness in physicians is widely underreported; most physicians are worried about losing their medical license for having a mental health diagnosis that is often required to be reported to the state board of medicine..$^{2-4}$ One might imagine that having untreated mental illness might put physicians at higher risk of suicide.

In fact, physicians are at greater risk of suicide than other people. Physicians are approximately twice as likely to suicide than others. ${ }^{5}$ The United States loses approximately up to 400 physicians annually due to physician suicide ${ }^{6}$ the statistics are even worse for women physicians. ${ }^{7}$ In fact, physicians have the highest rate of suicide compared to any other profession. Again: most physicians do not seek treatment for mental health because of the stigma of mental illness within the medical community. ${ }^{7-11}$ "Physicians are more than twice as likely to kill themselves as non-physicians (and female physicians, three times more likely than their male counterparts). Some 400 doctors commit suicide every year". ${ }^{11}$ Despite horror stories that I had heard and read surrounding punitive consequences of seeking treatment for mental health, ${ }^{12,13}$ - I did. I would like to note that there is a concern for increasing burnout among physicians ${ }^{13,14}$ - and that this differs from clinical diagnoses of depression, anxiety, Post Traumatic Stress Disorder (PTSD), etc. I knew that I fit the criteria for something beyond burnout. I knew it was important - it was necessary - for me to get help. For me, that was more important that the concerns I and others had about repercussions of seeking care or having a mental health diagnosis. ${ }^{15}$

Perfection is the expectation for physicians. ${ }^{16}$

Consider patient satisfaction scores. Patients must fill out anonymous surveys about their experience. PressGaney is one of the better-known surveys..$^{17}$ The anonymous patient satisfaction scores are based on mailed (or emailed) forms that asked for numerical rankings (on a scale of 1-10) as well as allowing for write-in comments. The patient satisfaction scores are used to determine
Medicare Advantage financial bonuses to medical institutions. To get these bonuses, patient satisfaction scores have to be in the 90th percentile. Mine were not perfect and I had enormous pressure to get better scores than $90 \%$ of neurologists in the state. Because of low response rates, my numbers were actually not statistically significant (which did not matter to my clinic). I was also competing with doctors who were not seeing straightforward neurology patients - I was also competing with pain specialists, sleep doctors, academic physicians, etc. I got numerous anonymous negative responses directed toward other doctors in my group. I got complaints about a staff member's cleavage. I got innumerable complaints about the billing department, and I got plenty of comments bemoaning the length of the survey.

My point is that I developed medical issues from this for which I actively sought professional help.

Here is a description of what some institutions offer doctors to help them be 'more well': ${ }^{18}$

"It's Resident Wellness Week at the children's hospital, and one of the coordinators has put ice cream in the resident fridge. Those of us who are working overnight shifts can't make it to most of the Wellness Week events - an aromatherapy session, a free yoga class, a whole hour where the hospital therapy dogs are available for us - so the ice cream is an effort to make us feel included. The coordinator comes by the cluster of computers in the emergency room where we are sitting to tell us about it. At this moment, I happen to be placing a call to the orthopedic surgeons about a 19-month-old girl with a spiral fracture of the femur. I have already examined the kid, reviewed her $x$-rays and ordered her a dose of morphine. I have learned the name of her stuffed rabbit Bunny. And after I talk to the surgeons I will call the child abuse team.

The surgeon lets me know that they will plan to place a SPICA splint in the morning, so I should admit the kid to orthopedics.

"And you're calling CPS?" he asks me. Spiral fractures are a classic sign of child abuse - a wound that is very difficult for a child to cause herself.

"Yeah, CPS is already here", I say.

"Who did it?"

"Her dad, presumably. She was alone with her dad when it happened. And the dude has a history".

"Is her dad with her?" the surgeon asks me.

This is when the coordinator appears before our bank of computers. "There's ice cream in the fridge for you guys," she says, "so be sure to take a break and get some".

I cover the mouthpiece of the phone with my hand and thank her.

"Happy Wellness Week!" she says, and waves goodbye. 
I uncover the mouthpiece. "Yeah." I tell the surgeon. "Her dad's in the room."

No amount of meditation or ice cream or chamomile tea or melatonin or anything else I tried could fix my anxiety, insomnia, depression.

Here is another account of what is done to help medical doctors face being 'unwell': ${ }^{11}$

"Hospitals and residency programs recognize the toll residency takes on the mental stability and physical health of new doctors. In 2003, work hours were capped at 80 hours a week for all residency training programs. Residents are provided confidential counseling services to help cope with stress. My residency program offers writing workshops and monthly reflection rounds. We have a wellness committee that organizes social events such as bonfires on the beach and visits from therapy dogs".

Perhaps some people do not benefit from beach bonfires or therapy dogs. These examples are from residency programs which provide more support than when one is in practice; however, even if my clinic had offered a bonfire or therapy dog - it would have only made things worse for me. Minimizing human suffering to something that is curable by having a cute, loving animal or a bonfire was just cruel. We already had 5 loving pets and a fire pit at our house. We had lost 2 of them; one had a devastating stroke, and one had severe pancreatitis and we had him in a home Intensive Care Unit (ICU) which required roundthe-clock care. Having a therapy dog at work would have been so very cruel.

These sorts of offerings by wellness committees are Band-Aids for a California wildfire - they may help that splinter you get from a burning log, but they do nothing for the wildfire.

I became very anxious about not being able to sleep. Many sleep specialists say that cognitive behavioral therapy should help with anxiety surrounding sleep; however, I had tried this to no avail. I had tried every non-prescription medication option that I could come up with and all of the ones others recommended (with the exception of cannabis, as it is still federally illegal; even though it is legalized in my state, I was highly concerned about the loss of my medical license were I to try it). When I saw my doctor, he resumed the medication regimen that I had not needed for years, and I was able to continue my career and my life without disruption because I was no longer ruminating all night long. I cannot emphasize enough just how helpful this was.

However, my clinic was concerned about my patient satisfaction scores. I met with the chief medical officer who suggested cocking my head like a dog to convey to my patients that I was listening. This did not seem helpful to me, and I felt that it was very insulting to not only me, but my patients. I had always listened intently to my patients. They may not have appreciated that I was listening because I was forced to stare at a computer screen to input their story into medical records. I wanted to capture their words into their record rather than trying to paraphrase it later. Taking notes by hand would not have allowed me to do that, as the electronic medical records systems are now mandated. I doubt that cocking my head would have done the trick.

My scores did not improve. They remained approximately in the top $25^{\text {th }}$ percentile which would not bring in the financial bonus to the clinic. That required advancing further up on the bell curve that was to become my nemesis.

Six months after meeting with the chief medical officer, the clinic had another doctor shadow me. He previously had good rapport with patients but he no longer really saw many of his own. He shadowed many doctors and physician assistants who were not reaching the $90^{\text {th }}$ percentile bell curve mark. His feedback was that I had good rapport with patients and had many strengths, but one of his suggestions was that I should touch my patients more. I was uncomfortable touching patients without a medical reason or consent. He had other suggestions, some of which I found offensive; I implemented others that seemed reasonable. My scores did not improve. They remained stable. I was still approximately in the top $25^{\text {th }}$ percentile.

Some of the responses were because I could not give them the diagnosis for which they had hoped. Those complaints were my responsibility; in fact, all of the complaints were - including those directed at things far beyond my reach - other health care providers, the phone bank, the billing department. This was in the first few years of my career. I was supposed to have a mentor but did not - others around me were suffering in their own ways: my work partner's daughter was dying and my chair hated neurology patients and wanted to leave the department. I was seeing the majority of all of our new patients myself. The clinic wanted us to see more patients, more quickly, and run what amounted to a walk-in neurology clinic. This was an impossible, highly unrealistic expectation.

I had to discuss patient satisfaction scores every 6 months during my semi-annual reviews. After the first couple of reviews, I became really anxious about them. At first, I saw a naturopath to try to address this without medication. I followed her regimen for a few months with no results. She told me to envision putting on a superhero cape every time I went to work - this technique did not help me; if anything, it made things worse.

When you are under scrutiny for being perceived as unpopular and experienced unpopularity in childhood, it is even worse. (For me, the Washington Physicians Health Program (WPHP) later used this as a psychological measure to keep me compliant). After I saw the naturopath, I saw the psychiatrist. The medication he prescribed allowed me to continue to function. I was surviving. My patient satisfaction scores did not budge, but I was not suffering and did my best. 
One day when speaking with my department chair, whom I considered a friend, I mentioned that I was seeing a psychiatrist for the mood issues. He replied that he had never seen a psychiatrist, but his Primary Care Physician (PCP) had prescribed antidepressants when he was going through a divorce. Because I came from an environment where PCPs did not treat mood problems, I had not considered this option. Seeing a psychiatrist and my lessthan-90th percentile patient satisfaction scores were two black marks that triggered the referral to the WPHP. My career was in jeopardy. ${ }^{12,19}$

The state PHPs claim that they are there to help 'impaired' physicians. In reality, they act as forensic specialists for the medical boards which control physician licensure. ${ }^{19}$ In Washington state, the medical board is known as the Washington Medical Commission (WMC). The historical mission of PHPs was to treat drug and alcohol addicted physicians in Alcoholic/Narcotic Anonymous programs. ${ }^{2}$ Their overreach now includes any medical or mental health-related condition that could possibly cause impairment. ${ }^{20}$ This overreach has been used legally to describe a wide range of conditions including identifying as homosexual. ${ }^{21}$ They also include multiple sclerosis, anxiety, depression, sleep issues, bipolar disorder under what they claim to monitor in lieu of being reported to the WMC. In reality, they are not equipped to deal with issues outside of the scope of substance use disorders. ${ }^{20}$

I was not referred to WPHP for substance abuse or suspected impairment of any kind. Even my employer misunderstood WPHP's purpose, thinking it was like an employee assistance program. My former clinic has since made the decision to never again refer anyone to WPHP because of what happened to me. I really want to believe that the clinic, of which I was part owner, was simply ignorant. Were they not, they would be in violation of Americans with Disabilities Act (ADA) regulations.

I was very surprised that at my first visit with the WPHP, I met with a psychiatrist and two others in a boardroom. I sat across the table from the 3 of them, who were spread out along the other side. I was grilled for approximately an hour by an aggressive investigator. This was not the behavior of any psychiatrist I had ever known. I felt like I was being interrogated by police, except that I had not been read any rights and was not counseled to obtain an attorney. The understanding was that I was there 'willingly'. When your career is threatened for not complying with demands - this is not actually willingly. It is forced and it is coerced. Being in that room, I was under duress. Nothing being discussed was surrounding communication at all.

I was also coerced to undergo witnessed urine screen and blood testing. I will describe the witnessed urine screen later. As a neurologist, I knew that this testing was irrelevant to my problems. Then I was shocked to learn that WPHP uses non-FDA approved laboratory tests in their evaluations. It never occurred to me that they approach al- most all of their physician clients with an a priori assumption of substance abuse - even though my employer explicitly stated that was not a concern and this is documented in WPHP's file on me. This is in sharp contrast to a standard diagnostic approach by ignoring the great variety of human disabilities, WPHP pigeonholes all of their clients into the only category they can use. I thought I had been referred to get help with communication skills. You can imagine my confusion. In their paperwork on me, they documented me as having a 'lack of insight' during the evaluation. How does one have insight when one is blindsided - having been told one thing, and then arriving to find a completely different situation at hand?

After the first visit, I was told that I had to undergo a 5-day inpatient psychiatric evaluation. I live in Washington State. For some reason, WPHP uses no facilities in the Pacific Northwest. I had the option of going to Alabama, Arkansas, or Denver. I opted for Denver because it was the closest, I could get a direct flight, they were university-affiliated, and did not use polygraphs as the others did - this is a debunked forensic procedure and is not evidence-based as in medical practice. I could not fathom why evaluation facilities would be using polygraphs for a psychiatric evaluation. As it turns out, the whole process is a forensic procedure, rather than the help that PHPs claim to provide. Again - this is a forensic and not clinical process. This is all conducted without being told one's rights or being advised to obtain an attorney.

There are good quality clinics in the Pacific Northwest to which I could have gone. It is astounding to me that the president-elect of the Federation of State Physician Health Programs who is on faculty at the University of Washington works at a facility that is not deemed acceptable for physician evaluation. The cognitive dissonance that hits me when I try to understand this is extreme. I was not given a choice to be anywhere closer to home. I was not allowed an opportunity to have this evaluation done as an outpatient. I had to spend more than $\$ 7000$ out of pocket to do this 'willingly'; however, if I did not comply with this demand, I would have been reported to the WMC for non-compliance, and the WMC could suspend or revoke my medical license. I had to take 3 weeks off of work waiting for a vacancy at the facility.

When I first arrived in Denver, all of my belongings except my clothing and a couple of books were taken from me. My phone was taken and I had no means of contacting family or friends. I was isolated in a locked psychiatric facility for a forensic evaluation that nobody warned me about. I was not allowed an attorney; I was not read any rights; there was no due process. I was emotionally battered by psychologists, psychiatrists, and a chaplain. This made me physically ill - especially the religious part. I was forced to attend Alcoholics Anonymous (AA) meetings during which the religious undertones rang so loudly.

I spent my $40^{\text {th }}$ birthday there, coerced into compliance by a threatening and hostile punitive program: the 
WPHP and the Federation of State Physician Health Programs (FSPHP) system.

The staff expectation when I checked in was that I would be there for 90 days: this was news to me. The man who did my intake evaluation was shocked when the only luggage I had was a backpack of items to get me through 5 days. When I left on day 5 , he told me that I was the only person he had ever seen who was allowed to go home after the evaluation without the required 90 days stay. The internal medicine doctor who did my initial evaluation was surprised: Every other physician had been required to stay for 90 days. The facility confirmed that I did not have any substance abuse issues and that I had a diagnosis of anxiety. Nevertheless, my medical insurance was billed for a week of detoxification when there was no detoxification warranted. This cost tens of thousands of dollars. The psychiatrist in Denver tried to coerce me to stay for 90 days in rehab - for mood issues. This made absolutely no sense to me at all. After this traumatic experience, the WPHP demanded that I sign a two-year behavioral health contract which included frequent unscheduled witnessed urine collections for substance abuse. The witnessed urine testing was not a recommendation of the Colorado facility and not standard medical practice. Only physicians in PHP treatment are subjected to this intrusion - whether they are being treated/monitored for substance use disorders, or they are not. WPHP demanded it despite knowing that I am a survivor of sexual assault.

I was diagnosed with anxiety and dysthymia - which I had already sought treatment for on my own and to which I had a good response. My chosen treating psychiatrist and my helpful medication were taken away, and WPHP said that I should not talk about this to anyone. Hearing that I should not talk about things to anyone - it felt very much like an abusive situation, wherein the abuser threatens the abused into silence.

The witnessed urine tests were very invasive as disclosed in the following testimony from my hearing regarding my medical license. This has not been modified and is directly from the transcriptionist:

"You have to call in every morning and punch in the number that they gave you, and i told you whether you had to go provide urine that day.

$Q$. What time of the morning would you make that call?

A. The earliest you could make the call was 5:00 a.m. I started - because this whole process was stressful, I started waking up earlier and earlier and earlier, worried about whether I would have to go that day because it would make me change my work schedule to accommodate getting to the testing center on time.

Q. Because what time did you show up for work? A. 8:00.

Q. So you're expected to be at work at 8:00. And how long did you stay at the clinic on a typical day?
A. On a typical day, between 4:00 and 5:00.

Q. Okay. And the testing facility was open what hours?

A. Until 4:30 or 5:00.

Q. And it opened at what time in the morning?

A. Eight o'clock - or it might have been 7:30.

Q. Okay. So, you had to fit it - did you ever have to leave the clinic and then go back to work after?

$A$. There were a couple of times where a patient cancelled in the middle of the day and I was able to go over, but that wasn't generally the case.

Q. Okay. And forgive me. I interrupted you. I was asking you what it was like to comply with this testing requirement.

A. It was really difficult. It was really, really difficult, and it became more and more difficult as the months went on.

Q. Can you say more about that?

A. It kept - I mean, it was so frequent. There were days I would have to go two times in a row.

Q. Two days in a row?

A. Two days in a row. You basically had to be able to urinate on the spot-on command. So usually on the days that I knew I would have to go, I would hold my urine through the entire day so that I actually had to go and could go at the end of the day. Q. Wow. And I know this isn't easy, but can you give us a bit more detail about the testing?

A. Yeah. After you washed your hands in a certain way, you went into the bathroom with someone to accompany you. In my case it was a female. I was told that there should never be a female in with a male or a male in with a female. You have to pull down your pants and sit on the toilet and you would have to sit in such a way that your labia are visualized by the person watching you. You would then have to pee in the cup. Sometimes, once that was done and you handed over the specimen, they would turn around and give you a little more privacy. Other times, they would just keep watching. On days where I would have my menstrual cycle, I would have to explain that there was a tampon in place because that is a foreign object in that area. And then one day - I think it was the last time I went for testing - urine testing, I could not make it to my normal testing center in time. I had to work too late. The other testing center was open later, so I went there. It was a confusing building. No one seemed to know where I was supposed to go. I finally found it. They brought me into the restroom. I really, really tried to go. I was, like, kind of stressed out about it because of the time. They were going to close soon also. So, you can only sit in the bathroom or the restroom for a certain period of time before they make you leave and wait and come back later to get you. And while I was sitting in the 
room waiting, I realized - I'm sorry. This is really hard to talk about. I realized that I had to defecate and that was pushing on my bladder in such a way that unless I could get that out, I wouldn't be able to pee - urinate. So, when I was taken back into the restroom, I explained to the woman that I was really sorry. Things were in the way. I have to get them out before I'd be able to pee. So, she watched me as I defecated. Before I was done, she - she told me to flush, which is a little bit hard to do when you're holding a specimen cup, defecating, and you don't know which side the handle is on. And she looked so disgusted, and I felt so ashamed, but I was able then to pee in a cup.

Q. Thank you. I'm sorry to have to ask you these questions.

I had to speak with a WPHP social worker via Skype every month. I told her that it was really, really hard for me to go through this over and over. Her indifferent response was "It's just for another few months".

All of my urine tests were negative for any substance - licit or illicit - but they did not allow this invasive testing to cease. Much, much later (more than a year after I quit the program), I was informed that WPHP could have tested other body fluids (saliva or blood), but the WPHP did not offer this as an alternative. The WPHP was absolutely aware that I was a survivor of sexual assault - and was having trauma due to the witnessed urine testing. I cannot describe how demoralizing it was, knowing that strangers were being paid to look at my genitals when it was unnecessary.

The forensic urine testing was also very expensive, but I knew that if I refused to comply with all of their demands, I would be reported to the WMC, at the time they were known as Medical Quality Assurance Committee (MQAC), and that my license could be license suspended or revoked.

Needless to say, during this time, my anxiety grew worse. The WPHP told me that the medication I had been taking for anxiety and insomnia was no longer an option. In fact - no treatment for anxiety or insomnia was allowed - including over the counter medications. In fact, medications such as diphenhydramine, Albuterol, Robitussin, etc. are also not allowed; nor is hand sanitizer. The WPHP required me to discontinue clonazepam without consulting my prescribing physician. Unsurprisingly, I began to experience a recurrence of severe insomnia, nightmares, and the worst anxiety of my life. This led to a 4 day stretch when I did not sleep at all. It was utterly disabling. I knew that my physical and mental health were being damaged. I also know that I was no longer in a condition to treat patients given my lack of sleep and anxiety. It was at this point that I preemptively left my job.

Before I was sent to WPHP, no one had any concerns about my skill or safety to practice medicine. No patient harm occurred or was alleged. No patient complained about the care I provided. But in January 2018, I quit my job thinking that it would end the psychological torture of the WPHP; because I stopped complying with WPHP, I was reported to the $\mathrm{WMC}$ who suspended my license.

The Washington Assistant Attorney General prosecuting my case first tried to get me to settle my case; I refused to do this. She then tried to convince me to have a closed hearing which I also refused. During my hearing with the WMC the assistant director of the WPHP stated that I was safe to practice up until I stopped complying with its demands. However, the inverse was the case - because of WPHP, I felt unsafe to practice and ceased complying with WPHP in order to restore my health.

At my hearing, the assistant director of the WPHP stated that my witnessed urine collections were so frequent because they suspected I would exploit any amount of time between screenings to abuse drugs or alcohol. Their baseline expectation is that doctors are addicts and frauds. The assistant director stated that the reason full genital inspection was necessary, including witnessed removal of tampons, was because I might put a balloon filled with someone else's urine in my vagina.

The judge presiding over the hearing made the decision that in order to get my license back, I would have to do whatever the WMC said to do, even if that meant sending me back to WPHP. The judge made this decision because no WMC members were present at my hearing they all cancelled at the last minute the prior evening. Were it a requirement to go back to the WPHP - I never would. They required me to undergo and relive sexual assault. I would never consent to going back to an abuser.

I lost everything after being referred to WPHP. I lost my job, my medical license, and shortly thereafter, my board certification from the American Board of Psychiatry and Neurology. I was reported to the National Physician Databank which will hinder any potential future job offers were my license to be reinstated.

I also lost my health and wellbeing.

To this day I wonder how, were I able to go back into practice, I could be better at helping; I am also not sure how anything about this process was to help my communication skills.

For doctors and other health care professionals: what happened to me could happen to you. It could happen to any physician who is referred to WPHP, and likely any PHP nationwide. The director of the WPHP is the president-elect of the Federation of State Physician Health Programs. He is responsible for what happened to me - and he will soon be presiding over every PHP in the US.

$\mathrm{He}$ is also dismissive of and possibly unaware of the high morbidity and mortality of physicians; in fact, he is more concerned about his stakeholders than the physicians who have been harmed via the WPHP and FSPHP:

"[T]here remains a small minority of physicians who are not willing or able to effectively engage with their state physician health program (PHP). 
Such cases are often complicated and heartbreaking, resulting in a cascade of distressing personal and professional consequences that can irrevocably impact the physician, colleagues, patients and families. Under these circumstances, it is not surprising that a few will become disgruntled, intent on unfairly disparaging PHPs and the PHP model. Their public protestations and allegations are shielded from scrutiny by strict confidentiality protections that preclude PHPs from responding with facts that might prove illuminating. These one-sided stories can generate sympathetic support from well-intentioned, but often misguided, champions of perceived injustice who draw upon these anecdotes as evidence that PHPs mistreat physicians and that the PHP model is broken. This phenomenon is not new or unexpected given the nature of our work and, because most know otherwise, it has not appreciably tarnished WPHP's reputation or weakened our stakeholders' support."

I would like to point out that this was published approximately one week after I, along with others, made statements at the Washington State Medical Association on October 12, 2019 regarding harm suffered at the hands of the WPHP. To be told that our stories are essentially value-less and ineffective at 'tarnishing the reputation of the WPHP" or weakening the support of their stakeholders is telling in terms of the priority of the WHPP - the WPHP is by no means an entity in place to 'help' physicians. To me - it also means that there are countless others out there who have also suffered harm at the hands of the WPHP who have not been able to speak out. Some of these - it is unknown just how many - are due to death. As it stands, the WPHP had not been collecting data on the cases of physician suicide on the watch of the WPHP, which is why the resolution was a necessity.

The rate of suicide by physicians is higher than expected - even when estimated by other medical professionals. ${ }^{10}$ The Washington State Medical Association (WSMA) just passed resolutions to start tracking the rate of physician suicide, including those involved with the WPHP and the state medical board, at their meeting on October 12-13, 2019. It is astounding to me that the WPHP spoke out against the WPHP-related resolution?.

Since this experience, I have learned that it has happened to other physicians. ${ }^{12,21-26}$

One of the most recent reports is from September 29, $2019 .{ }^{27}$

At a time of health care shortage, it is appalling that medical boards allow the PHPs to abuse physicians. I am not surprised that suicides have occurred. In fact, the suicide rate of physicians is the highest of any profession in the country. In the midst of my experience with the WPHP, I almost died by my own hand more than once. I am actually surprised that I am still alive today. Because of the WPHP I stared death in the face and yet, I somehow survived.

Beyond the damage I have suffered, what happened to me had serious adverse effects on my family, colleagues, and patients. The medical board and WPHP do not care about that. WPHP's demands cost me millions of dollars in future lost income and so much more that is not financial in nature. The medical board and the WPHP also cost me my career and nearly my life- and yet I am somehow still alive. I am grateful to the attorneys, politicians, and other advocates who are stepping up to confront this.

I still, at night, often lie awake thinking of my patients; however, it is not crippling as I have access to helpful medication again. It breaks my heart thinking how badly I wanted to help them and prevent their suffering and yet could not. I went into medicine with express desire to help and heal. I will never let that go. I did, however, take a vow to first do no harm. The best thing that I have ever done was to leave my job when I realized that an organization led by psychiatrists - many of whom are in their positions as part of their rehabilitation from substance use disorder ${ }^{28}$ was causing me harm. This harm is something from which I will never fully recover. They espouse 'recovery' which in their model is something which will never end. The concept of recovery is that you will eventually recover from the illness or injury. Their concept of recovery is a lifelong state of inertia. Of course, the medical board and the WPHP were decidedly unsympathetic as to the harm they caused. This became evident at their statements at the WSMA and as well as Chris Bundy's newsletter article shortly published shortly thereafter ${ }^{22}$ which are clearly exhibiting gas lighting toward those who have been harmed at their hand.

I fight against the stigma toward mental health troubles - which are no more than the normal responses of what we experience in our profession - but this experience made it clear to me that until regulatory bodies which reinforce stigma are destroyed and rebuilt, more doctors will continue to commit suicide as a way out. I would like to iterate that my near-suicide was not due to any medication; lack of access to a necessary medication was paramount. I know, without question, that had I had access to the medication which was instrumental in controlling my anxiety, I would still be a practicing physician. I would not have walked away from the profession that I spent more than a decade training for. For me, the removal of a medication was far more disabling than anything else.

I'm no longer just a survivor of sexual assault; I am a survivor of an additional form of repeated sexual assault at the hands of the WPHP that was required as a condition for me to continue working in my career. Most importantly, I am now the survivor of near-suicide caused by a so-called Physician 'Health' Program, which among many other abuses, subjected me to cruel dehumanizing experiences and forcing me to relive the trauma of prior sexual assault. Because of everything - I am not able to be a prac- 
ticing physician, so I am now working as a cheese monger. But - I am alive.

Nevertheless, I have persisted.

And I will not keep quiet. Not anymore.

https://www.youtube.com/watch?v=QZD05-ZvQFs

\section{References}

1. Mata DA, Ramos MA, Bansal N, et al. Prevalence of depression and depressive symptoms among resident physicians: a systematic review and meta-analysis. JAMA 2015;314:2373-83.

2. Wright J. In the belly of the american society of addiction medicine beast. The Stanton Peele Addiction Website 2000. Available from: https://www.peele.net/lib/talbott.html. Accessed: November 2019

3. Gold KJ, Andrew LB, Goldman EB, Schwenk TL. I would never want to have a mental health diagnosis on my record: a survey of female physicians on mental health diagnosis, treatment, and reporting. Gen Hosp Psy 2016;43:51-7.

4. Miles SH. A piece of my mind. A challenge to licensing boards: the stigma of mental illness. JAMA 1998;280:865.

5. Rose KD, Rosow I. Physicians who kill themselves. Arch Gen Psych 1973;29:800-5.

6. Andrew LB. Physician Suicide. Medscape 2018. Available from: https:/emedicine.medscape.com/article/806779overview. Accessed: November 2019.

7. Lindeman S, Laara E, Hakko H, Lonnqvist J. A systematic review on gender-specific suicide mortality in medical doctors. BJP 1196;168:274-9.

8. Giles SM. Insurance helps to brush physician depression under the rug. CMAJ 2018;190:E227.

9. Collier R. Physician suicide too often "brushed under the rug". CMAJ 2017;189:E1240-1.

10. Gavin K. Study: physicians don't report or treat their own mental illness due to stigma. University of Michigan Health 2016. Available from: https://labblog.uofmhealth.org/industry-dx/study-physicians-dont-report-or-treat-their-own-mental-illness-due-to-stigma Accessed: November 2019.

11. Sinha P. Why do doctors commit suicide? New York Times 2014. Available from: https://www.nytimes.com/2014/09/ 05/opinion/why-do-doctors-commit-suicide.html Accessed: November 2019.

12. Anderson P. Physician health programs: more harm than good? Medscape 2015. Available from: https://www.medscape.com/viewarticle/849772. Accessed: November 2019.

13. The Lancet. Physician burnout: the need to rehumanise health systems. Lancet 2019;394:1591.

14. Devitt M. Massachusetts groups call physician burnout public health crisis. American Association of Family Physicians 2019. Available from: https://www.aafp.org/news/focus-onphysician-well-being/20190208burnoutcrisis.html. Accessed: November 2019.

15. American Society for Suicide Prevention. Healthcare professional burnout, depression and suicide prevention. Available from: https://afsp.org/our-work/education/healthcare- professional-burnout-depression-suicide-prevention/ Accessed: November 2019.

16. Dagnone JD. Commentary: the physician as person framework: how human nature impacts empathy, depression, burnout, and the practice of medicine. Can Med Educ J 2017;8:e97-8. Available from: https://www.ncbi.nlm.nih. gov/pmc/articles/PMC5766225/

17. Wake Forest Baptist Health [Internet]. About the press ganey survey. Available from: https://lexington.wakehealth.edu/ Press-Ganey-Survey.htm Accessed: November 2019.

18. Pearson R. When doctors can't afford to feel. Daily Beast 2017. Available from: https://www.thedailybeast.com/whendoctors-cant-afford-to-feel Accessed: November 2019.

19. Emmons RS, Manion K, Andrew LB. Systematic abuse and misuse of psychiatry in the medical regulatory-therapeutic complex. J Am Physic Surg 2018;23:110-4. Available from: https://www.jpands.org/vol23no4/emmons.pdf

20. Lawson ND, Boyd JW. How broad are state physician health program descriptions of physician impairment? Subst Abuse Treat Prev Policy 2018;13:30.

21. Disrupted Physician 2015 [Internet]. Gay doctor coerced by Physician Health Program (PHP) into mandated 12-step treatment and monitoring for sex addiction: The slippery slope begins. Available from: https://disruptedphysician. com/2015/05/20/gay-doctor-coerced-by-physician-healthprogram-php-into-mandated-12-step-treatment-and-monitoring-for-sex-addiction-the-slippery-slope-begins-2/ Accessed: November 2019.

22. Bundy C. WPHP report: setting the record straight, part 1. Washington Medical Commission 2019. Available from: https://wmc.wa.gov/sites/default/files/public/Newsletter/4. WPHpReport.pdf Accessed: November 2019.

23. Glaser G. American doctors are killing themselves and no one is talking about it. Daily Beast 2015. Available from: https://www.thedailybeast.com/american-doctors-arekilling-themselves-and-no-one-is-talking-about-it. Accessed: November 2019.

24. Doctor left destitute after seeking help from physician health program. KSDK 2019. Available from: https://www.ksdk. com/article/news/local/doctor-left-destitute-after-seekinghelp-from-physician-health-program/63-99720f38-5c5c43c6-9c4c-c0f522ddc8c4 Accessed: November 2019

25. Med School Tutors 2017 [Internet]. (MedEd)itorial: The dark side of physician health programs. Available from: https://www.medschooltutors.com/blog/the-dark-side-ofphysician-health-programs. Accessed: November 2019.

26. Disrupted Physician [Internet]. Letters from those abused and afraid. Available from: https://disruptedphysician.com/ letters/ Accessed: November 2019.

27. Wible P. Beloved doctor dies in physician health program. Her husband wants to know why. Ideal Medical Care 2019. Available from: https://www.idealmedicalcare.org/beloveddoctor-dies-in-physician-health-program-her-husbandwants-to-know-why/ Accessed: November 2019.

28. Disrupted Physician 2014 [Internet]. Three shells and a peaASAM, FSPHP, and LMD. Available from: https://disruptedphysician.com/2014/03/16/three-shells-and-a-pea-asam-f sphp-and-lmd/ Accessed: November 2019. 